When cold the mould was broken open and the coins broken away from the runners. The author suggests that on one of the two opposing faces an obstruction was often deliberately left between the side runner and the coin mould, providing a small notch which enabled the coin the more easily to be detached.

The question as to whether this coin foundry was legitimate or not is discussed by the author, who concludes-possibly on somewhat scanty evidencethat these moulds were not, in fact, the product of a forger. Whether this be so or not is quite immaterial, however, from the point of view of the most interesting information provided regarding a technique employed at this very early date. A comparison is also made with other conjectured reconstructions of Indian and other coin moulds of different dates and localities. In the latter cases, however, more material is needed to settle the details of the process with the same certainty which has been possible in the case of the Rohtak procedure. To the metallurgist and numismatist alike, this contribution is one of outstanding interest.

F. C. THOMPSON

"Memoirs of the Numismatic Society of India", No. 1, Bombay, 1945.

\section{ATOMIC ENERGY EXHIBITION : THE ATOM TRAIN}

$\triangle$ FTER a tour lasting six and a half months, during A which the Atomic Energy Exhibition, organised by the Atomic Scientists' Association, visited twenty. five of the main centres in England, Scotland and Wales, the exhibition came to a close on May 28. Efforts to secure an extension in Great Britain failed; but the exhibition will continue its existence abroad. The Council of the Atomic Scientists' Association, as well as the Ministry of Supply and other owners of equipment, have agreed to lend the exhibits to the United Nations Educational, Scientific and Cultural Organisation and the Lebanese Government for incorporation in an exhibition at the Unesco Conference in Beirut in October. Later it will probably tour several countries in the Middle East and, possibly, various European countries. Although the administration of the tour is left to Unesco, the Atomic Scientists' Association will be closely connected with it, and the atomic energy part of the exhibition will be known as that of the British Atomic Scientists' Association.

In Great Britain the exhibition was an outstanding success and excelled all hopes. It was visited by more than 146,000 people, making an average daily attendance of 1,000 , which is 80 per cent of the maximum capacity. In many places people were queueing up for several hours. 85 per cent of the visitors came especially to see the exhibition, many of them making long trips for this purpose.

The reaction of the public was learnt from the answers of more than 1,100 people to a questionnaire handed out to a random sample of visitors. They show that the visitors represented a fair cross-section of the British public as regards occupations, with a slight bias in favour of the intellectual classes. 95 per cent of the public thought it worth while coming, and 91 per cent said that they had learnt something from the exhibition. The most interesting parts were found to be the counters and models ( 32 per cent) and the peaceful uses (24 per cent); the atom bomb section was the main item of interest for only 7 per cent. Quite a large number of people expressed surprise that atomic energy could be used for constructive purposes as well. The main criticism of the exhibition was that it was not big enough and too crowded.

The guide book to the exhibition sold extremely wall. Altogether more than 50,000 copies were sold or presented, making it the most popular and widespread publication on atomic energy.

The performance of the technical equipment, most of which was very delicate and tricky to operate, was extremely satisfying. Some of the experiments were demonstrated publicly for the first time and only a few years ago could not have been made to work reliably even with the best care in the laboratory. Here they were subjected to the most adverse conditions, to the movement of the train on a 1,900mile journey, to differences of temperature ranging from $30^{\circ}$ to $100^{\circ} \mathrm{F}$., to a wide range of voltages in the various places and, above all, to the heavy hands of about 130,000 adults and 16,000 inquisitive children.

Not only has the equipment withstood the test magnificently, but also it has beaten all records for endurance of this type of apparatus. The scaling units are supposed to have a life-time of 200 hours, and yet during the 1,600 hours of operation of five scaling units, only one valve had to be replaced. Throughout the whole tour, each Geiger counter had to be replaced only once. The total time when the exhibits were out of commission amounted to less than 1 per cent and the total expenditure on main. tenance of equipment, including replacement of films, fluorescent tubes, etc., was less than $£ 50$.

All this is evidence of the good quality and high. class workmanship of the British firms who manufactured it ; it is also a tribute to the technical staff who looked so well after the maintenance of the equipment.

The Atomic Energy Weeks, which were organised in conjunction with the exhibition, were also very successful and the lectures and film shows were well attended.

Summing up, it can be concluded that the exhibition achieved its main object-that of educating an appreciable fraction of the British public in matters of atomic energy.

\section{ROTHAMSTED EXPERIMENTAL STATION \\ REPORT FOR 1946}

$\mathrm{T}$ HE return to peace-time activities at Rothamsted Experimental Station enabled much of the fundamental and long-range work to be resumed, and the report for 1946 now issued includes a short account of such investigations, as well as of new work undertaken by the various departments. There are departments of physics, chemistry, soil microbiology, botany, crop physiology, statistics, plant pathology, biochemistry, entomology, insecticides and fungicides, and one for the study of bees. This list of departments indicates the very wide scope of the work at Rothamsted, and it is impossible not to be impressed by the advantages that must accrue from the ready contacts that are possible between the workers in the various sections. The experimental farm, together with that of Woburn, one on heavy and the other on light soil, offers every facility to the 